\title{
Mental Health and Chemical Dependency Services at US Cancer Centers
}

Shehzad K. Niazi, MD, FRCPC 1,2 ; Aaron Spaulding, PhD²,3; Emily Brennan, MPH²,3; Sarah K. Meier, PhD'; Julia E. Crook, PhD; Lauren F. Cornell, MD5 ; Sikander Ailawadhi, MD ${ }^{6}$; Matthew M. Clark, PhD; and Teresa A. Rummans, MD ${ }^{1,7}$

\begin{abstract}
Background: It is standard of care and an accreditation requirement to screen for and address distress and psychosocial needs in patients with cancer. This study assessed the availability of mental health $(\mathrm{MH})$ and chemical dependency (CD) services at US cancer centers. Methods: The 2017-2018 American Hospital Association (AHA) survey, Area Health Resource File, and Centers for Medicare \& Medicaid Services Hospital Compare databases were used to assess availability of services and associations with hospital-level and health services area (HSA)-level characteristics. Results: Of 1,144 cancer centers surveyed, $85.4 \%$ offered $\mathrm{MH}$ services and $45.5 \%$ offered CD services; only $44.1 \%$ provided both. Factors associated with increased adjusted odds of offering $\mathrm{MH}$ services were teaching status (odds ratio $[\mathrm{OR}], 1.76 ; 95 \% \mathrm{Cl}, 1.18-2.62$ ), being a member of a hospital system (OR, 2.00; 95\% Cl, 1.31-3.07), and having more beds (OR, 1.04 per 10-bed increase; $95 \% \mathrm{Cl}$, 1.02-1.05). Higher population estimate (OR, 0.98; $95 \% \mathrm{Cl}, 0.97-0.99)$, higher percentage uninsured (OR, 0.90; 95\% Cl, 0.86-0.95), and higher Mental Health Professional Shortage Area level in the HSA (OR, 0.99; $95 \% \mathrm{Cl}, 0.98-1.00)$ were associated with decreased odds of offering $\mathrm{MH}$ services. Government-run $(\mathrm{OR}, 2.85 ; 95 \% \mathrm{Cl}, 1.30-6.22)$ and nonprofit centers $(\mathrm{OR}, 3.48 ; 95 \% \mathrm{Cl}, 1.78-6.79)$ showed increased odds of offering $C D$ services compared with for-profit centers. Those that were members of hospital systems $(\mathrm{OR}, 1.61 ; 95 \% \mathrm{Cl}$, $1.14-2.29)$ and had more beds (OR, 1.02; 95\% Cl, 1.01-1.03) also showed increased odds of offering these services. A higher percentage of uninsured patients in the HSA (OR, $0.92 ; 95 \% \mathrm{Cl}$, 0.88-0.97) was associated with decreased odds of offering CD services. Conclusions: Patients' ability to pay, membership in a hospital system, and organization size may be drivers of decisions to co-locate services within cancer centers. Larger organizations may be better able to financially support offering these services despite poor reimbursement rates. Innovations in specialty payment models highlight opportunities to drive transformation in delivering $\mathrm{MH}$ and $\mathrm{CD}$ services for high-need patients with cancer.
\end{abstract}

J Natl Compr Canc Netw 2021;19(7):829-838 doi: $10.6004 /$ jnccn.2020.7657

\footnotetext{
${ }^{1}$ Department of Psychiatry \& Psychology, ${ }^{2}$ Robert D. and Patricia E. Kern Center for the Science of Health Care Delivery, and ${ }^{3}$ Department of Health Services Research, Mayo Clinic, Jacksonville, Florida; ${ }^{4}$ Robert D. and Patricia E. Kern Center for the Science of Health Care Delivery, Mayo Clinic, Rochester, Minnesota; ${ }^{5}$ Department of General Internal Medicine, and ${ }^{6}$ Department of Hematology, Mayo Clinic, Jacksonville, Florida; and ${ }^{7}$ Department of Psychiatry \& Psychology, Mayo Clinic, Rochester, Minnesota.
}

\section{Background}

Nearly $40 \%$ of patients with cancer have clinically significant psychiatric comorbidities, ${ }^{1-3}$ and $50 \%$ have reported significant distress. ${ }^{4}$ According to results from the National Epidemiologic Survey on Alcohol and Related Conditions-III (NESARC-III), patients diagnosed with cancer in the year of the survey had a higher 12-month prevalence of posttraumatic stress disorder, bipolar disorder, substance use disorder, and attempted suicide than patients with no cancer diagnosis. ${ }^{5}$ Additionally, the relative rates of mental and substance use disorders have been shown to increase in the months prior to cancer diagnosis and remain elevated 10 years after diagnosis. ${ }^{6}$ Furthermore, studies have shown that alcohol use increases the risk of breast, ${ }^{7}$ upper digestive tract, liver, and renal cancers. ${ }^{8}$

Hydes et $\mathrm{al}^{9}$ found that women consuming one bottle of wine in a week have an associated increase in the absolute risk of cancer, and that this risk is equivalent to the increased absolute risk of smoking 10 cigarettes per week. Using population-attributable fraction methodology, Shield et $\mathrm{al}^{10}$ estimated that 144,000 cases of breast cancer and 38,000 deaths caused by breast cancer could be attributable to alcohol consumption and that there was likely a dose-response relationship. An important distinction is to differentiate between moderate alcohol consumption and alcohol use disorder. In one study, the consumption of at least 6 grams of alcohol per day after a breast cancer diagnosis was associated with an increased risk of breast cancer recurrence. ${ }^{11}$ Similarly, smoking is a well-known risk factor for cancer, ${ }^{12}$ and active smoking status is associated with poorer outcomes. ${ }^{13-18}$ In patients with prostate cancer, smoking is associated with increased risk of recurrence and prostate cancer-specific mortality, whereas quitting for $\geq 10$ years mitigates that increased risk..$^{19}$ In another study, active smokers 1 year after prostatectomy were at higher risk of prostate cancer recurrence. ${ }^{20}$

See JNCCN.org for supplemental online content. 
Psychiatric comorbidities, including substance use disorders, are associated with a significant burden for patients with cancer and their family members. ${ }^{21}$ These comorbidities, especially depression, ${ }^{22}$ influence adherence to cancer treatment ${ }^{23}$ and are associated with poorer quality of life, ${ }^{24,25}$ increased cost of care, ${ }^{26-29}$ and increased mortality. ${ }^{30,31}$ However, effective treatments are available, ${ }^{32}$ and may even improve cancer survival. ${ }^{31}$ The NCCN Clinical Practice Guidelines in Oncology (NCCN Guidelines) for Distress Management use the term distress to describe psychological (ie, cognitive, behavioral, emotional), social, physical and spiritual challenges experienced by patients with cancer, and advises that timely assessment and identification of distress can lead to effective distress management, which improves cancer treatment. ${ }^{33}$ Screening for and addressing psychosocial needs by appropriately trained mental health $(\mathrm{MH})$ professionals is one of the Commission on Cancer's (COC) accreditation standards for cancer centers. ${ }^{34}$ Furthermore, to address distress adequately, a multidimensional construct and collaboration among various disciplines is needed. However, $96 \%$ of counties in the United States have an acute shortage of MH professionals. ${ }^{35}$

It is critical to assess the availability of $\mathrm{MH}$ and chemical dependency (CD) services to patients with cancer. This need is compounded in the midst of the COVID-19 pandemic and its resultant impact on cancer care. ${ }^{36-38}$ Although other specialties such as primary care may help, ${ }^{39}$ the availability of $\mathrm{MH}$ services at cancer centers is important to address patient needs in a timely fashion and is in accordance with NCCN Guidelines and COC accreditation standards. As such, this study assessed the availability of MH and CD services at US cancer centers.

\section{Methods}

\section{Data Sources}

Data were obtained from the American Hospital Association (AHA) 2017-2018 Annual Survey of Hospitals and the 2017-2018 Area Health Resource File (AHRF) countylevel database. The AHA survey database includes responses from $>6,400$ US hospitals, with a response rate $>75 \%{ }^{40,41}$ All open and operational hospitals (ie, licensed and accredited by agencies as approved by Title 18 of the Social Security Act) were invited to participate in the survey. The database contains information about hospital characteristics, services offered, and staffing, and responses are validated through review, comparison, and member checking by the AHA. ${ }^{41}$ The AHA data were used under license for this study. The AHRF is publicly available and is compiled by the US Department of Health and Human Services Health Resources \& Services Administration from $>50$ sources. $^{42}$
For data analysis, the hospital information from the AHA to county-level data from the AHRF were merged using the Federal Information Processing Standards (FIPS) code for each hospital's county. Data were then aggregated to the health services area (HSA) level using a crosswalk file from the NCI SEER program. ${ }^{43}$ Hospital financial information was extracted from publicly available Centers for Medicare \& Medicaid Services (CMS) Hospital Cost Reports, which contain financial data reported by Medicare healthcare providers back to CMS. ${ }^{44}$ This was matched to hospital survey data using the hospitals' Medicare identification numbers.

\section{Measures}

All nonfederal cancer centers in the United States that responded to the AHA survey were included. Psychiatric services are defined in the AHA questionnaire as the provision of "acute or long-term care to patients with mental or emotional disorders, including patients admitted for diagnosis and those admitted for treatment of psychiatric disorders, on the basis of physicians' orders and approved nursing care plans. Long-term care may include intensive supervision to persons with chronic/severe mental illness." 40

For this analysis, hospitals were considered to offer $\mathrm{MH}$ services if they reported offering any of the following types of psychiatric services: consultation-liaison, emergency, geriatric, outpatient, partial hospitalization, or residential. Alcoholism/CD services are defined in the AHA questionnaire as the provision of "diagnosis and therapeutic services to patients with alcoholism or other drug dependencies. Includes care for inpatient/residential treatment for patients whose course of treatment involves more intensive care than provided in an outpatient setting or where patient requires supervised withdrawal." 40 Hospitals were considered to offer CD services if they reported offering inpatient, partial hospitalization, or outpatient alcohol/drug abuse or dependency services. Hospitals were considered to offer combination services if they reported offering both MH and CD services.

Other hospital-level variables assessed included hospital ownership, teaching status, hospital system membership, rural health clinic status, Medicare and Medicaid discharge percentages, and number of beds (operationalized in models to indicate an increase of 10 beds). Social work services are defined by AHA as "organized services that are properly directed and sufficiently staffed by qualified individuals who provide assistance and counseling to patients and their families in dealing with social, emotional, and environmental problems associated with illness or disability, often in the context of financial or discharge planning coordination." ${ }^{40}$ Social work services were also examined but the variable was not included in models, because the extent to which social workers provide the services relevant to the current assessment is 
not clear, and because of lack of variation within the sample. HSA variables included racial diversity index (2010), ${ }^{45}$ per capita personal income (2016), unemployment rate (among individuals aged $\geq 16$ years) (2017), population estimate (2017), median age (2010), percentage uninsured (among individuals aged $<65$ years) (2016), number of hospitals per 100,000 people (2016), number of community MH centers per 100,000 people (2017), number of federally qualified health centers per 100,000 people (2017), and Mental Health Professional Shortage Area (MHPSA) rating (2018). The racial diversity index was calculated from 2010 US Census population racial percentages using the Esri definition ${ }^{45}$ based on 6 racial groups. The index ranges from 0 (no diversity) to 100 and indicates the probability that 2 individuals chosen at random will be from different racial groups. The MHPSA level of the HSA was created by converting the MHPSA code for each county from a categorical format $(0=$ none, $1=$ whole county, $2=$ part county) to a continuous variable $(0=$ none, $50=$ part county, $100=$ whole county) and averaging it across all counties in the HSA. ${ }^{46}$ Hospital operating margin is the ratio of the difference of total operating revenue and total operating expense to total operating revenue and is calculated using CMS hospital financial data. ${ }^{47}$

\section{Statistical Methods}

Descriptive statistics were calculated overall and by $\mathrm{MH}$, $\mathrm{CD}$, and combination services. Medians and ranges are presented for continuous variables, and frequencies and percentages are presented for categorical variables. Associations between services and hospital- and HSA-level predictors were examined using unadjusted logistic regression models. Generalized linear mixed models adjusted for all predictors showing a trend toward association with services offered $(P<.20)$ and for the random intercepts of HSA region were then performed on all predictors. Odds ratios, 95\% confidence intervals, and $P$ values are presented for each model. The random effect of HSA was included to account for the similarity of cancer centers within a single HSA. $P$ values of $<.05$ were considered statistically significant, and analyses were not adjusted for multiple testing. Modeling was performed using PROC LOGISTIC and PROC GLIMMIX in SAS 9.4 (SAS Institute Inc).

\section{Results}

Descriptive statistics for the 1,144 cancer centers in the United States and the 448 HSAs in which they are located are shown in Table 1. Among all cancer centers, 977 (85.4\%) offered MH services, 520 (45.5\%) offered CD services, and 505 (44.1\%) offered combination services. Most centers were nonprofit (81.9\%), teaching hospitals $(75.3 \%)$, and members of hospital systems (79.4\%). Nearly all hospitals (98.7\%) offered social work services, and the median hospital size was 279 beds.
Table 1. Hospital and HSA Characteristics of US Cancer Centers

\begin{tabular}{|c|c|}
\hline Characteristic & Value \\
\hline Hospital, N & 1,144 \\
\hline \multicolumn{2}{|l|}{ Ownership } \\
\hline For-profit, n (\%) & $69(6.0)$ \\
\hline Government (nonfederal), n (\%) & $138(12.1)$ \\
\hline Nonprofit, n (\%) & $937(81.9)$ \\
\hline Teaching status, n (\%) & $861(75.3)$ \\
\hline Member of a hospital system, n (\%) & $908(79.4)$ \\
\hline Rural location, n (\%) & $126(11.0)$ \\
\hline $\begin{array}{l}\text { Medicare discharge percentage, } \\
\text { median (range) }\end{array}$ & $52.0(9.9$ to 86.1$)$ \\
\hline $\begin{array}{l}\text { Medicaid discharge percentage, } \\
\text { median (range) }\end{array}$ & $19.7(0.0$ to 70.6$)$ \\
\hline $\begin{array}{l}\text { Number of hospital beds, } \\
\text { median (range) }\end{array}$ & 279 (12 to 2,877$)$ \\
\hline Operating margin (2016-2018), median (range) & $6.1(-111.3$ to 160.6$)$ \\
\hline Mental health services, $\mathrm{n}(\%)$ & $977(85.4)$ \\
\hline Chemical dependency services, $\mathrm{n}(\%)$ & $520(45.5)$ \\
\hline Combination services, n (\%) & $505(44.1)$ \\
\hline HSA, N & 448 \\
\hline Diversity index (2010), median (range) & 29.7 (3.2 to 78.5$)$ \\
\hline $\begin{array}{l}\text { Per capita personal income (per } \$ 1,000 \text { USD) } \\
(2016) \text {, median (range) }\end{array}$ & 45.1 (24.5 to 116.0$)$ \\
\hline $\begin{array}{l}\text { Unemployment rate, among individuals } \\
\text { aged } \geq 16 \text { y (2017), median (range) }\end{array}$ & $4.5(2.2$ to 11.6$)$ \\
\hline $\begin{array}{l}\text { Population estimate (100,000 people) (2017), } \\
\text { median (range) }\end{array}$ & $2.2(0.1$ to 101.6$)$ \\
\hline $\begin{array}{l}\text { Median age (5-y increase) (2010), } \\
\text { median (range) }\end{array}$ & $7.8(5.7$ to 10.3$)$ \\
\hline $\begin{array}{l}\text { Percentage uninsured aged }<65 \text { y (2016), } \\
\text { median (range) }\end{array}$ & $7.9(2.8$ to 29.0$)$ \\
\hline $\begin{array}{l}\text { Hospitals per 100,000 people (2016), } \\
\text { median (range) }\end{array}$ & $1.8(0.0$ to 18.2$)$ \\
\hline $\begin{array}{l}\text { Community mental health centers per } 100,000 \\
\text { people (2017), median (range) }\end{array}$ & 0.0 (0.0 to 0.7$)$ \\
\hline $\begin{array}{l}\text { Federally qualified health centers per } 100,000 \\
\text { people (2017), median (range) }\end{array}$ & $1.9(0.0$ to 52.1$)$ \\
\hline $\begin{array}{l}\text { Mental Health Professionals Shortage Area } \\
\text { level (2017), median (range) }\end{array}$ & $50.0(0.0$ to 100.0$)$ \\
\hline
\end{tabular}

HSA-level statistics were calculated using all 1,144 hospitals, even if they are located in the same HSA.

Abbreviation: HSA, health services area.

\section{MH Services}

Descriptive statistics for all centers stratified by $\mathrm{MH}$ services are displayed in Table 2, and unadjusted logistic regression results are presented in Table 3. Factors included as adjustment variables included teaching status, hospital system membership, rural location, Medicare and Medicaid discharge percentages, number of beds, per capita income in the HSA, population estimate in 
Table 2. Hospital and HSA Characteristics by Mental Health Services

\begin{tabular}{|c|c|c|}
\hline Characteristic & No & Yes \\
\hline Total, N & 167 & 977 \\
\hline \multicolumn{3}{|l|}{ Hospital } \\
\hline \multicolumn{3}{|l|}{ Ownership } \\
\hline For-profit, n (\%) & 15 (9.0\%) & 54 (5.5\%) \\
\hline Government (nonfederal), n (\%) & $18(10.8 \%)$ & $120(12.3 \%)$ \\
\hline Nonprofit, n (\%) & $134(80.2 \%)$ & $803(82.2 \%)$ \\
\hline Teaching status, n (\%) & $90(53.9 \%)$ & $771(78.9 \%)$ \\
\hline Member of a hospital system, $\mathrm{n}(\%)$ & $118(70.7 \%)$ & 790 (80.9\%) \\
\hline Rural location, $n(\%)$ & $29(17.4 \%)$ & 97 (9.9\%) \\
\hline Medicare discharge percentage, median (range) & $56.6(18.5$ to 86.1$)$ & 51.4 (9.9 to 84.8$)$ \\
\hline Medicaid discharge percentage, median (range) & $16.2(0.0$ to 55.5$)$ & $20.1(1.6$ to 70.6$)$ \\
\hline Number of beds (per 10-bed increase), median (range) & $19.3(1.2$ to 60.4$)$ & $29.2(1.2$ to 287.7$)$ \\
\hline Operating margin (2016-2018), median (range) & $6.8(-33.2$ to 35.5$)$ & $5.9(-111.3$ to 40.6$)$ \\
\hline \multicolumn{3}{|l|}{ HSA } \\
\hline Diversity index (2010), median (range) & 31.4 (3.4 to 78.5$)$ & 29.5 (3.2 to 74.2$)$ \\
\hline Per capita personal income (per $\$ 1,000$ USD) (2016), median (range) & $43.8(27.0$ to 77.6$)$ & $45.4(24.5$ to 116.0$)$ \\
\hline Unemployment rate, among individuals aged $\geq 16$ y (2017), median (range) & 4.5 (2.3 to 8.2$)$ & $4.5(2.2$ to 11.6$)$ \\
\hline Population estimate $(100,000$ people) (2017), median (range) & $1.5(0.2$ to 101.6$)$ & $2.3(0.1$ to 101.6$)$ \\
\hline Median age (5-y increase) (2010), median (range) & $7.9(6.1$ to 10.3$)$ & $7.8(5.7$ to 10.2$)$ \\
\hline Percentage uninsured aged <65 y (2016), median (range) & $9.7(2.8$ to 25.4$)$ & $7.6(2.8$ to 29.0$)$ \\
\hline Hospitals per 100,000 people (2016), median (range) & $2.2(0.0$ to 18.2$)$ & $1.8(0.4$ to 18.2$)$ \\
\hline Community mental health centers per 100,000 people (2017), median (range) & $0.0(0.0$ to 0.6$)$ & $0.0(0.0$ to 0.7$)$ \\
\hline Federally qualified health centers per 100,000 people (2017), median (range) & $2.2(0.0$ to 52.1$)$ & $1.9(0.0$ to 46.9$)$ \\
\hline Mental Health Professionals Shortage Area level (2017), median (range) & $62.5(25.0$ to 100.0$)$ & $50.0(0.0$ to 100.0$)$ \\
\hline
\end{tabular}

Abbreviation: HSA, health services area.

the HSA, median age in the HSA, percentage uninsured in the HSA, hospitals per 100,000 people in the HSA, and MHPSA level in the HSA. After adjustment, teaching status (odds ratio [OR], 176; 95\% CI, 1.18-2.62), being a member of a hospital system (OR, 2.00; 95\% CI, 1.31-3.07), and having more beds (OR, 1.04 per 10-bed increase; 95\% CI, 1.02-1.05) were associated with significantly increased odds of offering $\mathrm{MH}$ services. Higher population estimate in the HSA (OR, 0.98; 95\% CI, 0.97-0.99), higher percentage uninsured in the HSA (OR, 0.90; 95\% CI, 0.86-0.95), and higher MHPSA level in the HSA (OR, 0.99; 95\% CI, 0.98-1.00) were significantly associated with reduced odds of offering $\mathrm{MH}$ services. The diversity index in the HSA was also statistically significant in adjusted models, with centers in HSAs with greater diversity showing reduced odds of offering MH services (OR, 0.98; 95\% CI, 0.97-0.99).

\section{Services}

Descriptive statistics for all centers stratified by CD services are displayed in Table 4, and unadjusted logistic regression model results are presented in Table 5. Factors included as adjustment variables included hospital ownership type, teaching status, hospital system membership, rural location, Medicare and Medicaid discharge percentages, number of beds, per capita income in the HSA, unemployment rate in the HSA, median age in the HSA, percentage uninsured in the HSA, hospitals per 100,000 people in the HSA, federally qualified health centers per 100,000 people in the HSA, and MHPSA level in the HSA. In adjusted models, government-run (OR, 2.85; 95\% CI, 1.30-6.22) and nonprofit centers (OR, 3.48; $95 \%$ CI, 1.78-6.79) showed significantly increased odds of offering CD services compared with for-profit centers, and those that were members of hospital systems (OR, 1.61; 95\% CI, 1.14-2.29) and had more beds (OR, 1.02; 95\% CI, 1.01-1.03) also showed significantly increased odds. Centers with a higher percentage of uninsured individuals in the HSA (OR, 0.92; 95\% CI, 0.88-0.97) and centers in HSAs with greater diversity showed reduced adjusted odds of offering CD services (OR, 0.97; 95\% CI, 0.96-0.99). 


\section{Table 3. Unadjusted and Adjusted Logistic Models for Mental Health Services}

\begin{tabular}{|c|c|c|c|c|}
\hline Characteristic & Unadjusted OR $(95 \% \mathrm{CI})$ & $P$ Value & Adjusted ${ }^{a}$ OR $(95 \% \mathrm{CI})$ & $P$ Value \\
\hline \multicolumn{5}{|l|}{ Hospital } \\
\hline \multicolumn{5}{|l|}{ Ownership } \\
\hline For-profit & Ref & Ref & Ref & Ref \\
\hline Government (nonfederal) & $1.85(0.87-3.95)$ & .22 & $1.93(0.80-4.63)$ & .14 \\
\hline Nonprofit & $1.67(0.91-3.04)$ & .35 & $1.07(0.53-2.14)$ & .85 \\
\hline Teaching status & $3.20(2.28-4.50)$ & $<.001$ & $1.76(1.18-2.62)$ & .006 \\
\hline Member of a hospital system & $1.75(1.21-2.54)$ & .003 & $2.00(1.31-3.07)$ & .002 \\
\hline Rural location & $0.53(0.33-0.82)$ & .005 & $1.48(0.85-2.57)$ & .16 \\
\hline Medicare discharge percentage & $0.97(0.96-0.99)$ & $<.001$ & $0.99(0.97-1.01)$ & .44 \\
\hline Medicaid discharge percentage & $1.04(1.02-1.06)$ & $<.001$ & $1.01(0.99-1.04)$ & .24 \\
\hline Number of hospital beds (per 10-bed increase) & $1.04(1.03-1.05)$ & $<.001$ & $1.04(1.02-1.05)$ & $<.001$ \\
\hline Operating margin (median 2016-2018) & $1.00(0.98-1.01)$ & .59 & $0.99(0.98-1.01)$ & .38 \\
\hline \multicolumn{5}{|l|}{ HSA } \\
\hline Diversity index (2010) & $1.00(0.99-1.01)$ & .59 & $0.98(0.97-0.99)$ & .007 \\
\hline Per capita personal income (per $\$ 1,000$ USD) (2016) & $1.03(1.01-1.05)$ & $<.001$ & $1.01(0.99-1.04)$ & .22 \\
\hline Unemployment rate, among individuals aged $\geq 16$ y (2017) & $0.99(0.86-1.15)$ & .91 & $1.03(0.86-1.23)$ & .75 \\
\hline Population estimate $(100,000$ people) (2017) & $0.99(0.98-1.00)$ & .16 & $0.98(0.97-0.99)$ & .002 \\
\hline Median age (5-y increase) (2010) & $0.80(0.60-1.07)$ & .13 & $0.81(0.58-1.13)$ & .21 \\
\hline Percentage uninsured aged $<65$ y (2016) & $0.92(0.89-0.95)$ & $<.001$ & $0.90(0.86-0.95)$ & $<.001$ \\
\hline Hospitals per 100,000 people (2016) & $0.93(0.87-0.99)$ & .021 & $0.98(0.90-1.08)$ & .68 \\
\hline Community mental health centers per 100,000 people (2017) & $3.23(0.31-33.93)$ & .33 & $0.71(0.06-7.86)$ & .78 \\
\hline Federally qualified health centers per 100,000 people (2017) & $0.99(0.96-1.02)$ & .45 & $1.00(0.96-1.04)$ & .97 \\
\hline Mental Health Professional Shortage Area level (2017) & $0.98(0.98-0.99)$ & $<.001$ & $0.99(0.98-1.00)$ & .044 \\
\hline
\end{tabular}

Abbreviations: HSA, health services area; OR, odds ratio.

aAdjusted for ownership, teaching status, system membership, rural location, Medicare percentage, Medicaid percentage, number of beds, per capita income in the HSA, population estimate in the HSA, median age in the HSA, percentage uninsured in the HSA, hospitals per 100,000 people in the HSA, Mental Health Professionals Shortage Area level in the HSA, and random effect of HSA.

\section{Combination MD/CD Services}

Descriptive statistics for all centers stratified by combination services are shown in supplemental eTable 1 (available with this article at JNCCN.org). Factors included as adjustment variables included hospital ownership type, teaching status, hospital system membership, rural location, Medicare and Medicaid discharge percentages, number of beds, per capita income in the HSA, unemployment rate in the HSA, median age in the HSA, percentage uninsured in the HSA, hospitals per 100,000 people in the HSA, federally qualified health centers per 100,000 people in the HSA, and MHPSA level in the HSA. After adjustment, government-run (OR, 2.76; 95\% CI, 1.27-6.03) and nonprofit centers (OR, 3.13; 95\% CI, 1.60-6.11) showed increased odds of offering combination services compared with for-profit centers (supplemental eTable 2). Centers that were members of hospital systems (OR, 1.56; 95\% CI, $1.10-2.21)$ and those with more beds (OR, 1.02; 95\% CI, 1.01-1.03) also showed significantly increased odds of offering them. Centers with a higher percentage uninsured in the HSA (OR, 0.92; 95\% CI, 0.87-0.96) also showed reduced odds. Centers in HSAs with greater diversity also showed reduced odds of offering combination services in adjusted models (OR, 0.97; 95\% CI, 0.96-0.99).

\section{Discussion}

This study of $>1,000$ cancer centers found that most cancer centers offered MH services, but only half offered $\mathrm{CD}$ services and even fewer offered both $\mathrm{CD}$ and $\mathrm{MH}$ services. Results indicated that cancer centers with more beds, academic cancer centers, and centers that were members of hospital systems were more likely to offer $\mathrm{MH}$ services. Cancer centers located in HSAs with a lower population, lower percentage of uninsured residents, and lower MHPSA levels showed increased odds of offering MH services. Larger cancer centers (more beds), members of a healthcare system, government-run or nonprofit centers (vs for-profit centers), and centers in 
Table 4. Hospital and HSA Characteristics by Chemical Dependency Services

\begin{tabular}{|c|c|c|}
\hline Characteristic & No & Yes \\
\hline Total, N & 624 & 520 \\
\hline \multicolumn{3}{|l|}{ Hospital } \\
\hline \multicolumn{3}{|l|}{ Ownership } \\
\hline For-profit, n (\%) & 55 (8.8\%) & $14(2.7 \%)$ \\
\hline Government (nonfederal), n (\%) & $87(13.9 \%)$ & $51(9.8 \%)$ \\
\hline Nonprofit, n (\%) & $482(77.2 \%)$ & $455(87.5 \%)$ \\
\hline Teaching status, n (\%) & 437 (70.0\%) & $424(81.5 \%)$ \\
\hline Member of a hospital system, $\mathrm{n}(\%)$ & 472 (75.6\%) & 436 (83.8\%) \\
\hline Rural location, $n(\%)$ & $86(13.8 \%)$ & $40(7.7 \%)$ \\
\hline Medicare discharge percentage, median (range) & $53.4(9.9$ to 86.1$)$ & 50.1 (11.5 to 84.8$)$ \\
\hline Medicaid discharge percentage, median (range) & $19.1(0.0$ to 70.6$)$ & $20.2(1.6$ to 63.8$)$ \\
\hline Number of beds (per 10-bed increase), median (range) & 25.4 (1.2 to 287.7$)$ & 31.9 (3.0 to 254.0$)$ \\
\hline Operating margin (2016-2018), median (range) & $6.1(-111.3$ to 140.6$)$ & $5.9(-50.2$ to 50.3$)$ \\
\hline \multicolumn{3}{|l|}{ Health services area } \\
\hline Diversity index (2010), median (range) & 29.8 (3.2 to 78.5$)$ & $28.3(5.4$ to 74.2$)$ \\
\hline Per capita personal income (per $\$ 1,000$ USD) (2016), median (range) & $44.0(27.0$ to 116.0$)$ & $46.3(24.5$ to 108.1$)$ \\
\hline Unemployment rate, among individuals aged $\geq 16$ y (2017), median (range) & $4.5(2.2$ to 11.6$)$ & $4.4(2.4$ to 11.6$)$ \\
\hline Population estimate $(100,000$ people) (2017), median (range) & $2.0(0.1$ to 101.6$)$ & $2.6(0.2$ to 101.6$)$ \\
\hline Median age (5-y increase) (2010), median (range) & $7.8(6.1$ to 10.3$)$ & 7.8 (5.7 to 9.2$)$ \\
\hline Percentage uninsured aged $<65 \mathrm{y}$, median (range) (2016) & $8.8(2.8$ to 25.4$)$ & $7.2(2.8$ to 29.0$)$ \\
\hline Hospitals per 100,000 people (2016), median (range) & $1.9(0.0$ to 18.2$)$ & $1.7(0.4$ to 18.2$)$ \\
\hline Community mental health centers per 100,000 people (2017), median (range) & $0.0(0.0$ to 0.6$)$ & $0.0(0.0$ to 0.7$)$ \\
\hline Federally qualified health centers per 100,000 people (2017), median (range) & $2.2(0.0$ to 52.1$)$ & $1.7(0.0$ to 42.2$)$ \\
\hline Mental Health Professionals Shortage Area level (2017), median (range) & $60.0(0.0$ to 100.0$)$ & $50.0(0.0$ to 100.0$)$ \\
\hline
\end{tabular}

Abbreviation: HSA, health services area.

HSAs with a lower percentage of uninsured residents were more likely to offer CD services. A greater diversity index score was associated with lower adjusted odds of offering $\mathrm{MH}$ and $\mathrm{CD}$ services, although the effect sizes were small.

It is reassuring that most cancer centers offered MH services, but lack of specialized CD services to address the comorbid substance use disorder at approximately $65 \%$ of the cancer centers is a significant concern. Substance use disorders are common among patients with cancer. One meta-analysis reported substance use disorder rates of $2 \%$ to $35 \%$ ( $18 \%$ for opioid use disorder and $25.5 \%$ for alcohol use disorder) ${ }^{48}$ The associated risks of additional cancers, negative influences on overall health, adverse effects on quality of life, and increased risk of cancer recurrence if substance use disorders are not addressed appropriately warrant both assessing and actively managing comorbid substance use disorders in patients with cancer. As an example, consider opioid use disorders in these patients. Cancer pain is common, and 1 in 3 patients also experiences noncancer pain. ${ }^{49}$ The use of opioids to address pain can become a challenge, especially in patients with preexisting or new-onset opioid use disorders. ${ }^{50-52}$ Careful evaluation to identify at-risk groups, early recognition and timely treatment of opioid use disorders, ${ }^{52}$ and access to specialized substance use disorder programs such as buprenorphine/naloxone ${ }^{51}$ and other nonpharmacologic treatments can be better accomplished when CD treatment services are available at cancer centers.

There are several possible explanations for the lack of $\mathrm{MH}$ and CD services at cancer centers. Policy barriers may make it challenging to offer $\mathrm{MH}$ and CD services. ${ }^{53-55}$ The Bipartisan Policy Center report identified insurance coverage and reimbursement barriers, workforce barriers, and administrative barriers limiting the integration of $\mathrm{MH}$ services. ${ }^{55}$ Our study found that cancer centers located in HSAs with higher uninsured populations were less likely to provide $\mathrm{MH}$ and $\mathrm{CD}$ services. Given the negative relationship between social economic status (the relevant hypotheses 
Table 5. Unadjusted and Adjusted Logistic Models for Chemical Dependency Services

\begin{tabular}{|c|c|c|c|c|}
\hline Characteristic & Unadjusted OR (95\% Cl) & $P$ Value & Adjusted $\mathrm{OR}(95 \% \mathrm{Cl})$ & $P$ Value \\
\hline \multicolumn{5}{|l|}{ Hospital } \\
\hline \multicolumn{5}{|l|}{ Ownership } \\
\hline For-profit & Ref & Ref & Ref & Ref \\
\hline Government (nonfederal) & $2.30(1.17-4.55)$ & .44 & $2.85(1.30-6.22)$ & .009 \\
\hline Nonprofit & $3.71(2.03-6.76)$ & $<.001$ & $3.48(1.78-6.79)$ & $<.001$ \\
\hline Teaching status & $1.89(1.43-2.50)$ & $<.001$ & $1.19(0.84-1.70)$ & .33 \\
\hline Member of a hospital system & $1.67(1.24-2.25)$ & $<.001$ & $1.61(1.14-2.29)$ & .008 \\
\hline Rural location & $0.52(0.35-0.77)$ & .001 & $1.11(0.68-1.83)$ & .67 \\
\hline Medicare discharge percentage & $0.98(0.97-0.99)$ & $<.001$ & $0.99(0.97-1.00)$ & .12 \\
\hline Medicaid discharge percentage & $1.01(1.00-1.02)$ & .041 & $0.99(0.98-1.01)$ & .38 \\
\hline Number of beds (per 10-bed increase) & $1.02(1.01-1.02)$ & $<.001$ & $1.02(1.01-1.03)$ & $<.001$ \\
\hline Operating margin (median 2016-2018) & $1.00(0.99-1.01)$ & .60 & $1.00(0.99-1.01)$ & .95 \\
\hline \multicolumn{5}{|l|}{ HSA } \\
\hline Diversity index (2010) & $1.00(0.99-1.01)$ & .59 & $0.97(0.96-0.99)$ & $<.001$ \\
\hline Per capita personal income (per $\$ 1,000$ USD) (2016) & $1.03(1.02-1.04)$ & $<.001$ & $1.01(0.99-1.02)$ & .51 \\
\hline Unemployment rate, among individuals aged $\geq 16$ y (2017) & $0.88(0.79-0.98)$ & .020 & $0.91(0.79-1.06)$ & .21 \\
\hline Population estimate (100,000 people) (2017) & $1.00(0.99-1.01)$ & .85 & $0.99(0.97-1.01)$ & .17 \\
\hline Median age (5-y increase) (2010) & $0.77(0.63-0.95)$ & .013 & $0.82(0.61-1.10)$ & .18 \\
\hline Percentage uninsured aged <65 y (2016) & $0.93(0.90-0.96)$ & $<.001$ & $0.92(0.88-0.97)$ & $<.001$ \\
\hline Hospitals per 100,000 people (2016) & $0.91(0.86-0.97)$ & .002 & $0.99(0.91-1.07)$ & .72 \\
\hline Community mental health centers per 100,000 people (2017) & $1.59(0.37-6.81)$ & .53 & $0.75(0.11-5.05)$ & .77 \\
\hline Federally qualified health centers per 100,000 people (2017) & $0.97(0.94-1.00)$ & .023 & $1.00(0.97-1.04)$ & .97 \\
\hline Mental Health Professionals Shortage Area level (2017) & $0.99(0.98-0.99)$ & $<.001$ & $1.00(0.99-1.00)$ & .19 \\
\hline
\end{tabular}

Abbreviations: HSA, health services area; OR, odds ratio.

${ }^{a} A d j u s t e d$ for ownership, teaching status, system membership, rural location, Medicare percentage, Medicaid percentage, number of beds, per capita income in the HSA, unemployment rate in the HSA, median age in the HSA, percentage uninsured in the HSA, hospitals per 100,000 people in the HSA, federally qualified health centers in the HSA, Mental Health Professionals Shortage Area level in the HSA, and random effect of HSA.

are reviewed by Hudson ${ }^{56}$ ) and $\mathrm{MH}$, this population may have the highest prevalence of $\mathrm{MH}$ and $\mathrm{CD}$ disorders. For-profit cancer centers were also significantly less likely to offer CD services than government-run and nonprofit centers. One possible explanation for this is poor reimbursement for $\mathrm{MH}$ and CD services. A national report found that $42 \%$ of the US population identified increased cost and insufficient insurance coverage as a major barrier to accessing $\mathrm{MH}$ care. ${ }^{57}$ Major federal MH laws have attempted to address the coverage and reimbursement barriers and to achieve parity. The Mental Health Parity Act of $1996^{58}$ temporarily removed the lifetime and annual limits for MH coverage. The Paul Wellstone and Pete Domenici Mental Health Parity and Addiction Equity Act (MHPAEA) of $2008^{59}$ made the parity permanent, but it did not apply to fee-for-service (FFS) plans. The Patient Protection and Affordability Care Act of $2010^{60}$ made $\mathrm{MH}$ services an "essential health benefit" for employerbased plans. Finally, the 21st Century Cures Act of
$2016^{61}$ sought to increase coordination and accountability for federal MH offerings. Despite this concerted effort, coverage parity of MH services remains a challenge. In fact, recent interpretations of these laws, state-waivers, and short-term insurance plans with limited MH coverage are threatening the progress made over the years. ${ }^{55}$

Although coverage of $\mathrm{MH}$ services is a key factor, it is not sufficient to guarantee unhindered access. Despite progress in coverage reforms, barriers to $\mathrm{MH}$ provider access, even among insured patients, are welldocumented, with a recent National Alliance on Mental Illness survey reporting barriers to access in the form of narrow networks, distance to specialized care, and $\mathrm{MH}$ providers not accepting new patients. ${ }^{62}$ Our study underscores yet another key barrier: the immediate care delivery model responsible for the patient's care episode failing to support and facilitate access to necessary $\mathrm{MH}$ and CD services. In the case of cancer care, this may occur at a time when these services are acutely needed, 
yet perhaps most likely to be neglected given the aggregate burden of navigating the care delivery system during an episode of cancer. In this respect, cancer centers have an opportunity to treat the full needs of the patient during a cancer episode by ensuring co-location of $\mathrm{MH}$ and CD services. When that is not possible, cancer centers may formalize collaborative relations with other community partners to address patients and their caregivers' MH needs.

Our study also suggests that the impact of some barriers are perhaps mitigated when cancer centers have a greater number of beds or are part of a larger hospital system. An economic analysis studying the impact of hospital mergers ${ }^{63}$ noted that when hospitals pool their resources, they can become more efficient, realize savings, are able to innovate, improve quality of care, and reduce operating expenses by approximately $2.5 \%$. The net effect is that they are able to offer more services, and care becomes more comprehensive. ${ }^{64}$

Notably, the Oncology Care Model (OCM) provides a key example of how the value-based payment paradigm may be leveraged to address persisting $\mathrm{MH}$ and CD access challenges. Distress screening and addressing psychosocial needs are both OCM requirements. OCM participants are assessed based on whether they facilitate treatment of both the $\mathrm{MH}$ and the cancer treatment needs of their patients. ${ }^{65}$ This model illustrates the opportunity to drive $\mathrm{MH}$ care delivery transformation through specialty value-based payment model design-a policy lever that could influence care delivery design outside of larger systems.

Academic medical centers (AMCs) care for high-cost and high-need patients ${ }^{66}$ and have begun to consider this a potential opportunity in the era of value-based payment models. ${ }^{67}$ Existing evidence showing that comorbid $\mathrm{MH}$ and $\mathrm{CD}$ conditions in patients with cancer are associated with increased cost of cancer care ${ }^{27,29}$ provides an impetus to have such services available for these patients. Furthermore, AMCs also provide training to future clinicians, increasing the likelihood of availability of comprehensive services. The combination of these factors makes it more likely for AMCs to offer MH and CD services.

HSAs with a lower percentage of MHPSAs were more likely to offer MH services. However, it is probable that cancer centers are more successful in hiring MH professionals than organizations with fewer resources. Despite this, shortage of MH professionals remains a significant factor. Greater flexibilities in payment for telehealth and alternative modes of care delivery may offer one partial solution for this persisting challenge.

We also found a significant association between diversity index in the HSA and reduced odds of offering $\mathrm{MH}, \mathrm{CD}$, and combination services. Although the effect size was small and could be a statistical artifact, the existence of disparities in $\mathrm{MH}$ and cancer care for minority patients is well-documented. ${ }^{68,69}$ Further research is needed to understand how various underrepresented groups of patients with cancer may be impacted by the availability of these services near where they live.

Limitations exist in our study. First, we used only secondary data sources. The AHA is self-reported by hospitals, and thus there is a risk of incompleteness and/or incorrectness. Additionally, responses to the AHA survey can show whether such services are available, yet they do not account for the adequacy of the services. Thus, there is a risk of overestimating the access to these services. Additionally, use of these data prevented us from clearly identifying whether $\mathrm{MH}$ and $\mathrm{CD}$ services were being provided by psychiatrists, psychologists, or other $\mathrm{MH}$ professionals. Our use of the term "MH services" is consistent with the term used in the source database, wherein AHA defines the nature of services but does not explicitly ask who at those centers is providing such services. In other words, services that "offer immediate initial evaluation and treatment to patients with mental or emotional disorder" could conceivably be provided by a psychiatrist or a psychologist. Hence the generic term was used but does not indicate the specific availability of prescribers (psychiatrists) versus nonprescribers (psychologists, advanced practice psychiatric nurses, social workers, licensed professional counselors, and marriage and family therapists) at these cancer centers. Additionally, previous research shows varying degrees of shortages for these two categories. ${ }^{35}$ Furthermore, some of the AHRF data are from the 2010 US Census and may not be current, and therefore could potentially affect the results. However, both the AHA and AHRF are commonly used, high-quality datasets. Finally, in this cross-sectional study, we could only measure associations among variables but could not define causality.

\section{Conclusions}

Considering the prevalence of psychiatric comorbidities in patients with cancer, the effect of distress on outcomes, and the importance placed on screening for and addressing psychosocial needs within NCCN Guidelines and $\mathrm{COC}$ accreditation standards, one would expect that cancer centers will continue to work on integrating $\mathrm{MH}$ and $\mathrm{CD}$ services in cancer care. In particular, the lack of availability of CD services in cancer centers is a significant concern. System-level, workforce, and insurance-related factors affect the likelihood of provision of these services. Innovative payment models can transform the delivery of $\mathrm{MH}$ and $\mathrm{CD}$ services 
to patients with cancer. These models will be most effective when they not only establish requirements but also directly support transformation in settings that lack resources and specialized knowledge available in large systems and AMCs.

Submitted June 22, 2020; final revision received September 22, 2020; accepted for publication September 22, 2020. Published online March 4, 2021.

Author contributions: Study concept and design: Niazi, Spaulding. Data acquisition: Spaulding, Brennan, Crook. Data analysis and interpretation: Niazi, Spaulding, Brennan, Crook. Manuscript preparation: All authors. Critical revision: Meier, Crook, Cornell, Ailawadhi, Clark, Rummans
Disclosures: The authors have disclosed that they have not received any financial consideration from any person or organization to support the preparation, analysis, results, or discussion of this article.

Disclaimer: The data that support the findings of this study are available from the American Hospital Association. Restrictions apply to the availability of these data, which were used under license for this study. Data are available at https:// www.ahadata.com/aha-annual-survey-database-asdb/ with the permission of the American Hospital Association. Publicly available data for the Area Health Resource File can be found at https://data.hrsa.gov/data/download, and for the CMS Hospital Cost Reports can be found at https://www.cms.gov/ Research-Statistics-Data-and-Systems/Downloadable-Public-Use-Files/ Cost-Reports/Cost-Reports-by-Fiscal-Year.html.

Correspondence: Shehzad K. Niazi, MD, FRCPC, Department of Psychiatry, Mayo Clinic, 4500 San Pablo Road, Jacksonville, FL 32224 Email: niazi.shehzad@mayo.edu

\section{References}

1. Grassi L, Caruso R, Mitchell AJ, et al. Screening for emotional disorders in patients with cancer using the Brief Symptom Inventory (BSI) and the BSI-18 versus a standardized psychiatric interview (the World Health Organization Composite International Diagnostic Interview). Cancer 2018:124:2415-2426.

2. Kuhnt $\mathrm{S}$, Brähler $\mathrm{E}$, Faller $\mathrm{H}$, et al. Twelve-month and lifetime prevalence of mental disorders in cancer patients. Psychother Psychosom 2016;85:289-296.

3. Mitchell AJ, Chan M, Bhatti H, et al. Prevalence of depression, anxiety, and adjustment disorder in oncological, haematological, and palliative-care settings: a meta-analysis of 94 interview-based studies. Lancet Oncol 2011;12:160-174.

4. Mehnert A, Hartung TJ, Friedrich $M$, et al. One in two cancer patients is significantly distressed: prevalence and indicators of distress. Psychooncology 2018;27:75-82.

5. Mallet J, Huillard O, Goldwasser F, et al. Mental disorders associated with recent cancer diagnosis: results from a nationally representative survey. Eur J Cancer 2018;105:10-18.

6. Lu D, Andersson TM, Fall K, et al. Clinical diagnosis of mental disorders immediately before and after cancer diagnosis: a nationwide matched cohort study in Sweden. JAMA Oncol 2016;2:1188-1196.

7. Freudenheim JL. Alcohol's effects on breast cancer in women. Alcohol Res 2020;40:11.

8. Thygesen LC, Mikkelsen P, Andersen TV, et al. Cancer incidence among patients with alcohol use disorders-long-term follow-up. Alcohol Alcohol 2009;44:387-391.

9. Hydes TJ, Burton $R$, Inskip $H$, et al. A comparison of gender-linked population cancer risks between alcohol and tobacco: how many cigarettes are there in a bottle of wine? BMC Public Health 2019;19:316.

10. Shield KD, Soerjomataram I, Rehm J. Alcohol use and breast cancer: a critical review. Alcohol Clin Exp Res 2016;40:1166-1181.

11. Kwan ML, Kushi LH, Weltzien E, et al. Alcohol consumption and breast cancer recurrence and survival among women with early-stage breast cancer: the life after cancer epidemiology study. J Clin Oncol 2010;28: 4410-4416.

12. Ordóñez-Mena JM, Schöttker B, Mons U, et al. Quantification of the smoking-associated cancer risk with rate advancement periods: metaanalysis of individual participant data from cohorts of the CHANCES consortium. BMC Med 2016:14:62

13. Smith J, Nastasi D, Tso R, et al. The effects of continued smoking in head and neck cancer patients treated with radiotherapy: a systematic review and meta-analysis. Radiother Oncol 2019;135:51-57.

14. Sollie M, Bille C. Smoking and mortality in women diagnosed with breast cancer-a systematic review with meta-analysis based on 400,944 breast cancer cases. Gland Surg 2017;6:385-393.

15. Ben QW, Liu J, Sun YW, et al. Cigarette smoking and mortality in patients with pancreatic cancer: a systematic review and meta-analysis. Pancreas 2019;48:985-995.

16. Ordóñez-Mena JM, Walter V, Schöttker B, et al. Impact of prediagnostic smoking and smoking cessation on colorectal cancer prognosis: a metaanalysis of individual patient data from cohorts within the CHANCES consortium. Ann Oncol 2018;29:472-483.

17. Foerster B, Pozo C, Abufaraj M, et al. Association of smoking status with recurrence, metastasis, and mortality among patients with localized prostate cancer undergoing prostatectomy or radiotherapy: a systematic review and meta-analysis. JAMA Oncol 2018;4:953-961.
18. Duan W, Li S, Meng X, et al. Smoking and survival of breast cancer patients: a meta-analysis of cohort studies. Breast 2017;33:117-124.

19. Kenfield SA, Stampfer MJ, Chan JM, et al. Smoking and prostate cancer survival and recurrence. JAMA 2011;305:2548-2555.

20. Joshu CE, Mondul AM, Meinhold CL, et al. Cigarette smoking and prostate cancer recurrence after prostatectomy. J Natl Cancer Inst 2011 ; 103:835-838.

21. Caruso R, Nanni MG, Riba MB, et al. The burden of psychosocial morbidity related to cancer: patient and family issues. Int Rev Psychiatry 2017;29:389-402.

22. DiMatteo MR, Lepper HS, Croghan TW. Depression is a risk factor for noncompliance with medical treatment: meta-analysis of the effects of anxiety and depression on patient adherence. Arch Intern Med 2000;160: 2101-2107.

23. Theofilou P, Panagiotaki H. A literature review to investigate the link between psychosocial characteristics and treatment adherence in cancer patients. Oncol Rev 2012;6:e5.

24. Brown LF, Kroenke K, Theobald DE, et al. The association of depression and anxiety with health-related quality of life in cancer patients with depression and/or pain. Psychooncology 2010;19:734-741.

25. Faller $\mathrm{H}$, Brähler $\mathrm{E}, \mathrm{Härter} \mathrm{M}$, et al. Performance status and depressive symptoms as predictors of quality of life in cancer patients. A structural equation modeling analysis. Psychooncology 2015;24:1456-1462.

26. Habboush JY, Niazi SK, Naessens JM, et al. Patient-reported distress and medical expenses in patients receiving definitive radiation therapy. Int J Radiat Oncol Biol Phys 2016;96:E523-524.

27. Niazi S, Frank RD, Sharma M, et al. Impact of psychiatric comorbidities on health care utilization and cost of care in multiple myeloma. Blood Adv 2018;2:1120-1128

28. Waddle MR, Niazi S, Aljabri D, et al. Cost of acute and follow-up care in patients with pre-existing psychiatric diagnoses undergoing radiation therapy. Int J Radiat Oncol Biol Phys 2019;104:748-755.

29. Niazi SK, Naessens JM, White L, et al. Impact of psychiatric comorbidities on health care costs among patients with cancer. Psychosomatics 2020; 61:145-153

30. Ko A, Kim K, Sik Son J, et al. Association of pre-existing depression with all-cause, cancer-related, and noncancer-related mortality among 5-year cancer survivors: a population-based cohort study. Sci Rep 2019;9:18334.

31. Shim EJ, Lee JW, Cho J, et al. Association of depression and anxiety disorder with the risk of mortality in breast cancer: a National Health Insurance Service study in Korea. Breast Cancer Res Treat 2020;179: 491-498.

32. Grassi L, Nanni MG, Rodin G, et al. The use of antidepressants in oncology: a review and practical tips for oncologists. Ann Oncol 2018;29:101-111.

33. Riba MB, Donovan KA, Andersen B, et al. Distress Management, Version 3.2019, NCCN Clinical Practice Guidelines in Oncology. J Natl Compr Canc Netw 2019;17:1229-1249.

34. Commission on Cancer. Cancer Program Standards: Ensuring PatientCentered Care. Chicago, IL: American College of Surgeons; 2016.

35. Thomas KC, Ellis AR, Konrad TR, et al. County-level estimates of mental health professional shortage in the United States. Psychiatr Serv 2009;60: 1323-1328.

36. Nelson B. COVID-19 is shattering US cancer care. BMJ 2020;369:m1544.

37. The ASCO Post Staff. Survey shows COVID-19 pandemic is affecting patients' access to cancer care. American Society of Clinical Oncology. 
Accessed April 21, 2020. Available at: https://ascopost.com/news/ april-2020/survey-shows-covid-19-pandemic-is-affecting-patientsaccess-to-cancer-care/

38. Kutikov A, Weinberg DS, Edelman MJ, et al. A war on two fronts: cancer care in the time of COVID-19. Ann Intern Med 2020:172:756-758.

39. Jones D, Neal RD, Duffy SRG, et al. Impact of the COVID-19 pandemic on the symptomatic diagnosis of cancer: the view from primary care. Lancet Oncol 2020;21:748-750.

40. American Hospital Association. AHA Annual Survey Database. Accessed March 2, 2019. Available at: http://www.ahadata.com/aha-annual-surveydatabase

41. American Hospital Association. Data Collection Methods. Accessed March 2, 2019. Available at: https://www.ahadataviewer.com/about/data/

42. US Health Resources \& Services Administration. Data downloads: area health resource files. Accessed March 2, 2019. Available at: https:// data.hrsa.gov/data/download

43. National Cancer Institute: Surveillance, Epidemiology, and End Results Program. Health Services Areas (HSA). Accessed March 2, 2019. Available at: https://seer.cancer.gov/seerstat/variables/countyattribs/hsa.html

44. Centers of Medicare \& Medicaid Services. Cost Reports. Accessed April 11, 2019. Available at: https://www.cms.gov/research-statistics-data-andsystems/downloadable-public-use-files/cost-reports/

45. Esri Diversity Index. Accessed March 2, 2019. Available at: http:// downloads.esri.com/esri_content_doc/dbl/us/J10170_US_Diversity\% 20Index_2018.pdf

46. US Health Resources \& Services Administration. Technical Documentation for the County Area Health Resources File (AHRF): 2017-2018 Release. Accessed February 8, 2021. Available at: https://data.hrsa.gov/data/ download

47. Hospital Financial Indicators. Accessed March 2, 2019. Available at: https://www.ahd.com/definitions/FinlndWorksheetRef.pdf

48. Yusufov M, Braun IM, Pirl WF. A systematic review of substance use and substance use disorders in patients with cancer. Gen Hosp Psychiatry 2019;60:128-136.

49. Roberto A, Deandrea S, Greco MT, et al. Prevalence of neuropathic pain in cancer patients: pooled estimates from a systematic review of published literature and results from a survey conducted in 50 Italian palliative care centers. J Pain Symptom Manage 2016;51:1091-1102.

50. Kata $\mathrm{V}$, Novitch MB, Jones MR, et al. Opioid addiction, diversion, and abuse in chronic and cancer pain. Curr Opin Support Palliat Care 2018;12: 124-130

51. Moryl N, Filkins A, Griffo Y, et al. Successful use of buprenorphinenaloxone medication-assisted program to treat concurrent pain and opioid addiction after cancer therapy. J Opioid Manag 2020;16:111-118.

52. Pinkerton R, Hardy JR. Opioid addiction and misuse in adult and adolescent patients with cancer. Intern Med J 2017;47:632-636.
53. Mental Health and the Role of the States. Accessed December 29, 2020. Available at: https://www.pewtrusts.org/-/media/assets/2015/06/ mentalhealthandroleofstatesreport.pdf

54. Mauch D, Kautz C, Smith S. Reimbursement of Mental Health Services in Primary Care Settings. Accessed December 29, 2020. Available at: https://aims.uw.edu/resource-library/reimbursement-mental-healthservices-primary-care-settings

55. Bipartisan Policy Center. Integrating Clinical and Mental Health: Challenges and Opportunities. Accessed December 29, 2020. Available at: https:// bipartisanpolicy.org/wp-content/uploads/2019/03/Integrating-Clinical-andMental-Health-Challenges-and-Opportunities.pdf

56. Hudson CG. Socioeconomic status and mental illness: tests of the social causation and selection hypotheses. Am J Orthopsychiatry 2005;75:3-18

57. America's Mental Health 2018. Accessed December 29, 2020. Available at: https://www.cohenveteransnetwork.org/wp-content/uploads/2018/ 10/Research-Summary-10-10-2018.pdf

58. Mental Health Parity Act of 1996, Pub L No. 104-204, 110 Stat 2874 (1996).

59. Paul Wellstone and Pete Domenici Mental Health Parity and Addiction Equity Act of 2008, Pub L No. 110-343, 122 Stat 3765 (2008).

60. Patient Protection and Affordable Care Act of 2010, Pub L No. 111-148, 124 Stat 119-124 Stat 1025 (2010).

61. 21st Century Cures Act of 2016, Pub L No. 114-255, 130 Stat 1034 (2016).

62. National Alliance on Mental Illness. Doctor is Out: Continuing Barriers in Access to Mental and Physical Healthcare. Accessed May 12, 2020. Available at: https://www.nami.org/Support-Education/PublicationsReports/Public-Policy-Reports/The-Doctor-is-Out/DoctorlsOut

63. Noether M, May S. Hospital Merger Benefits: Views from Hospital Leaders and Econometric Analysis. Accessed May 12, 2020. Available at: https:// www.crai.com/sites/default/files/publications/Hospital-Merger-FullReport-_FINAL-1.pdf

64. American Hospital Association. The Benefits of Hospital Mergers. Accessed May 12, 2020. Available at: https://www.aha.org/news/blog/ 2017-11-08-benefits-hospital-mergers

65. Centers for Medicare \& Medicaid Services Innovation Center. Oncology Care Model Overview. Accessed May 12, 2020. Available at: https://innovation.cms.gov/Files/slides/ocm-overview-slides.pdf

66. Heisler M, DeMonner SM, Billi JE, et al. Medicaid managed care: are academic medical centers penalized by attracting patients with high-cost conditions? Am J Manag Care 2003;9:19-29.

67. Blumenthal D, McCarthy D, Shah TB. Academic medical centers and highneed, high-cost patients: a call to action. Acad Med 2018;93:1617-1619.

68. Cook BL, Trinh NH, Li Z, et al. Trends in racial-ethnic disparities in access to mental health care, 2004-2012. Psychiatr Serv 2017;68:9-16.

69. Pan HY, Walker GV, Grant SR, et al. Insurance status and racial disparities in cancer-specific mortality in the United States: a population-based analysis. Cancer Epidemiol Biomarkers Prev 2017;26:869-875. 


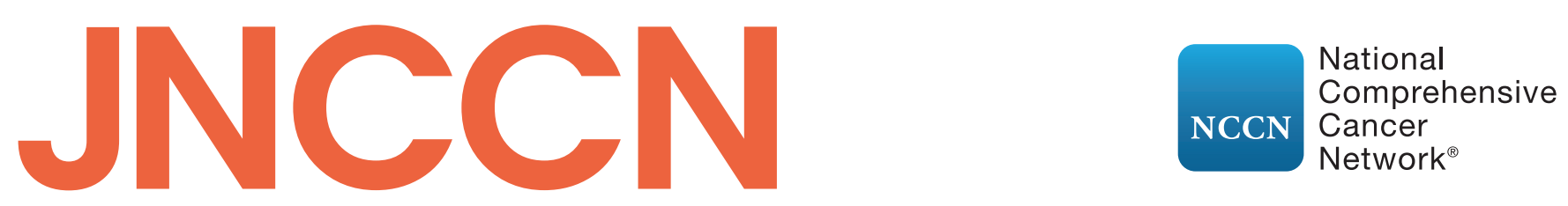

JOURNAL OF THE NATIONAL COMPREHENSIVE CANCER NETWORK

Supplemental online content for:

\section{Mental Health and Chemical Dependancy Services at US Cancer Centers}

Shehzad K. Niazi, MD, FRCPC; Aaron Spaulding, PhD; Emily Brennan, MPH; Sarah K. Meier, PhD; Julia E. Crook, PhD; Lauren F. Cornell, MD; Sikander Ailawadhi, MD; Matthew M. Clark, PhD; and Teresa A. Rummans, MD

J Natl Compr Canc Netw 2021;19(7):829-838

eTable 1: Hospital and HSA Characteristics by Combination Mental Health/Chemical Dependancy Services eTable 2: Unadjusted and Adjusted Logistic Models for Combination Mental Health/Chemical Dependancy Services 


\section{eTable 1. Hospital and HSA Characteristics by Combination MH/CD Services}

\begin{tabular}{|c|c|c|}
\hline Characteristic & No & Yes \\
\hline Total, $\mathrm{N}$ & 639 & 505 \\
\hline \multicolumn{3}{|l|}{ Hospital } \\
\hline \multicolumn{3}{|l|}{ Ownership } \\
\hline For-profit, n (\%) & 55 (8.6\%) & $14(2.8 \%)$ \\
\hline Government (nonfederal), n (\%) & $87(13.6 \%)$ & $51(10.1 \%)$ \\
\hline Nonprofit, n (\%) & $497(77.8 \%)$ & $440(87.1 \%)$ \\
\hline Teaching status, $\mathrm{n}(\%)$ & $446(69.8 \%)$ & $415(82.2 \%)$ \\
\hline Member of a hospital system, $\mathrm{n}(\%)$ & $486(76.1 \%)$ & $422(83.6 \%)$ \\
\hline Rural location, $n(\%)$ & $88(13.8 \%)$ & $38(7.5 \%)$ \\
\hline Medicare discharge percentage, median (range) & $53.2(9.9$ to 86.1$)$ & $50.1(11.5$ to 84.8$)$ \\
\hline Medicaid discharge percentage, median (range) & $19.0(0.0$ to 70.6$)$ & $20.6(1.6$ to 63.8$)$ \\
\hline Number of beds (per 10-bed increase), median (range) & $25.4(1.2$ to 287.7$)$ & 32.1 (3.0 to 254.0$)$ \\
\hline Operating margin (median 2016-2018), median (range) & $6.2(-111.3$ to 140.6$)$ & $5.9(-50.2$ to 50.3$)$ \\
\hline \multicolumn{3}{|l|}{ HSA } \\
\hline Diversity index (2010), median (range) & 29.9 (3.2 to 78.5$)$ & 27.9 (5.4 to 74.2$)$ \\
\hline Per capita personal income (per $\$ 1,000$ USD) (2016), median (range) & $44.0(27.0$ to 116.0$)$ & $46.5(24.5$ to 108.1$)$ \\
\hline Unemployment rate, among individuals aged $\geq 16$ y (2017), median (range) & $4.5(2.2$ to 11.6$)$ & $4.5(2.4$ to 11.6$)$ \\
\hline Population estimate (100,000 people) (2017), median (range) & $2.0(0.1$ to 101.6$)$ & $2.6(0.2$ to 101.6$)$ \\
\hline Median age (5-y increase) (2010), median (range) & $7.8(6.1$ to 10.3$)$ & 7.8 (5.7 to 9.2$)$ \\
\hline Percentage uninsured aged $<65$ y (2016), median (range) & $8.9(2.8$ to 25.4$)$ & $7.2(2.8$ to 29.0$)$ \\
\hline Hospitals per 100,000 people (2016), median (range) & $1.9(0.0$ to 18.2$)$ & $1.7(0.4$ to 18.2$)$ \\
\hline Community mental health centers per 100,000 people (2017), median (range) & $0.0(0.0$ to 0.6$)$ & $0.0(0.0$ to 0.7$)$ \\
\hline Federally qualified health centers per 100,000 people (2017), median (range) & $2.1(0.0$ to 52.1$)$ & $1.7(0.0$ to 42.2$)$ \\
\hline Mental Health Professionals Shortage Area level (2017), median (range) & $60.0(0.0$ to 100.0$)$ & $50.0(0.0$ to 100.0$)$ \\
\hline
\end{tabular}

Abbreviations: $\mathrm{CD}$, chemical dependency; $\mathrm{HSA}$, health services area; $\mathrm{MH}$, mental health. 
eTable 2. Unadjusted and Adjusted Logistic Models for Combination MH/CD Services

\begin{tabular}{|c|c|c|c|c|}
\hline Characteristic & Unadjusted OR $(95 \% \mathrm{Cl})$ & $P$ Value & Adjusted $^{\mathrm{a}} \mathrm{OR}(95 \% \mathrm{Cl})$ & $P$ Value \\
\hline \multicolumn{5}{|l|}{ Hospital } \\
\hline \multicolumn{5}{|l|}{ Ownership } \\
\hline For-profit & Ref & Ref & Ref & Ref \\
\hline Government (nonfederal) & $2.30(1.17-4.55)$ & .37 & $2.76(1.27-6.03)$ & 011 \\
\hline Nonprofit & $3.48(1.91-6.34)$ & $<.001$ & $3.13(1.60-6.11)$ & $<.001$ \\
\hline Teaching status & $2.00(1.50-2.65)$ & $<.001$ & $1.25(0.87-1.78)$ & .22 \\
\hline Member of a hospital system & $1.60(1.19-2.16)$ & .002 & $1.56(1.10-2.21)$ & .013 \\
\hline Rural location & $0.51(0.34-0.76)$ & .001 & $1.12(0.68-1.84)$ & .67 \\
\hline Medicare discharge percentage & $0.98(0.98-0.99)$ & .001 & $0.99(0.97-1.01)$ & .21 \\
\hline Medicaid discharge percentage & $1.01(1.00-1.02)$ & .021 & $0.99(0.98-1.01)$ & .49 \\
\hline Number of beds (per 10-bed increase) & $1.02(1.01-1.02)$ & $<.001$ & $1.02(1.01-1.03)$ & $<.001$ \\
\hline Operating margin (median 2016-2018) & $1.00(0.99-1.01)$ & 1.00 & $1.00(0.98-1.01)$ & .67 \\
\hline \multicolumn{5}{|l|}{ HSA } \\
\hline Diversity index (2010) & $1.00(0.99-1.01)$ & .65 & $0.97(0.96-0.99)$ & $<.001$ \\
\hline Per capita personal income (per $\$ 1,000$ USD) (2016) & $1.03(1.02-1.04)$ & $<.001$ & $1.01(0.99-1.02)$ & .54 \\
\hline Unemployment rate, among individuals aged $\geq 16$ y (2017) & $0.90(0.81-1.00)$ & .060 & $0.93(0.81-1.08)$ & .36 \\
\hline Population estimate (100,000 people) (2017) & $1.00(0.99-1.01)$ & .91 & $0.99(0.97-1.00)$ & .093 \\
\hline Median age (5-y increase) (2010) & $0.76(0.62-0.94)$ & .010 & $0.80(0.59-1.07)$ & .13 \\
\hline Percentage uninsured aged $<65$ y (2016) & $0.92(0.90-0.95)$ & $<.001$ & $0.92(0.87-0.96)$ & $<.001$ \\
\hline Hospitals per 100,000 people (2016) & $0.90(0.85-0.96)$ & .001 & $0.99(0.91-1.07)$ & .77 \\
\hline Community mental health centers per 100,000 people (2017) & $1.98(0.46-8.46)$ & .36 & $0.87(0.13-5.69)$ & .88 \\
\hline Federally qualified health centers per 100,000 people (2017) & $0.97(0.94-1.00)$ & .032 & $1.00(0.97-1.04)$ & .99 \\
\hline Mental Health Professionals Shortage Area level (2017) & $0.98(0.98-0.99)$ & $<.001$ & $0.99(0.99-1.00)$ & .13 \\
\hline
\end{tabular}

Abbreviations: $\mathrm{CD}$, chemical dependency; HSA, health services area; $\mathrm{MH}$, mental health; OR, odds ratio.

aAdjusted for ownership, teaching status, system membership, rural location, Medicare percentage, Medicaid percentage, number of beds, per capita income in the HSA, unemployment rate in the HSA, median age in the HSA, percentage uninsured in the HSA, hospitals per 100,000 people in the HSA, federally qualified health centers in the HSA, Mental Health Professionals Shortage Area level in the HSA, and random effect of HSA. 